\section{El ataque de lo doméstico. Un proyecto artístico para el cuestionamiento de la violencia machista en el hogar}

\author{
The attack of the domestic. An artistic project to question sexist \\ violence at home
}

Vanesa Cintas Muñoz.

Universidad de Granada (UGR), España

Recibido 01/05/2018

Revisado 25/05/2018

vanecint@hotmail.com

Aceptado 26/05/2018

Publicado 01/07/2018

\section{Resumen}

Conscientes del papel transformador del arte y de las posibilidades que nos ofrece para intervenir en la cotidianidad de la vida, en este texto, exponemos y analizamos el proyecto artístico El ataque de lo doméstico. Un proyecto que asume la práctica artística como investigación para cuestionar y denunciar el ejercicio de la violencia física y sexual hacia las mujeres y niñas/os ocurridas en el hogar patriarcal hostil. Un combate cara a cara con la violencia, con su silencio, sus tabúes y su escabrosa complicidad que se enfrenta crítica y artísticamente con esta realidad, dando voz a la experiencia y haciendo visible su rotundo ejercicio para reverberar así, las situaciones más traumáticas y poder, desde

\begin{abstract}
In this text we present and analyze the artistic project The attack of the domestic, keeping awareness of the transforming role of art and the possibilities it offers to intervene in everyday life. It is a project that understands artistic practice as a means to question and denounce physical and sexual violence exerted against women and children that has happened in the hostile, patriarchal home. It shows a face-to-face combat against violence, its silence, its taboos, and its lurid complicities. The project critically and artistically faces the reality of violence against women (and children) by giving voice to experience, denouncing the most traumatic situations in order
\end{abstract}

Para citar este artículo

Cintas Muñoz, Vanesa (2018). El ataque de lo doméstico. Un proyecto artístico para el cuestionamiento de la violencia machista en el hogar. Tercio Creciente, 14, págs. 17-36. https://dx.doi.org/10.17561/rtc.n14.4 
ISSN: 2340-9096

DOI: https://dx.doi.org/10.17561/rtc.n14.4 www.terciocreciente.com

Investigación el lenguaje del arte de la performance, manejarlas, subvertirlas o transformarlas. to be able to manage, subvert or transform them using the language of performance.

Palabras clave / Keywords

Arte, performance, violencia machista, espacio doméstico, investigación artística.

Art, performance, gender violence, domestic space, artistic research..

Para citar este artículo

Cintas Muñoz, Vanesa (2018). El ataque de lo doméstico. Un proyecto artístico para el cuestionamiento de la violencia machista en el hogar. Tercio Creciente, 14, págs. 17-36. https://dx.doi.org/10.17561/rtc.n14.4 


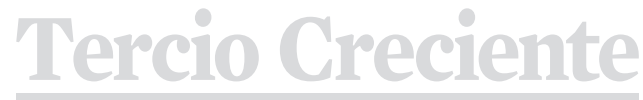

ISSN: 2340-9096

DOI: https://dx.doi.org/10.17561/rtc.n14.4
Investigación

\section{Introducción}

La violencia machista que acecha a las mujeres, niñas/os se encuentra instaurada en nuestra vidas y en los diferentes estratos e instituciones de nuestra sociedad occidental como consecuencia de las relaciones de poder social, cultural e históricamente establecidas entre hombres y mujeres y de los roles diferenciados atribuidos a unas y a otros que sirven de mecanismos para ejercer dicho poder y legitimar la violencia en los cuerpos femeninos.

Dicha violencia machista, se manifiesta de forma significativa en el espacio patriarcal de lo doméstico. Un espacio propicio para la violencia debido a su distanciamiento de lo público que aleja de su representación, las graves consecuencias de esta rígida estructuración y parcelación del ejercicio de poder y de violencia, la estricta escala jerárquica que lleva a la mujer a una situación de subordinación y sometimiento, basada en la supremacía masculina y en una noción de patriarcado, donde se excluyen todas las posibilidades de igualdad entre los sexos y géneros.

Bajo este horizonte y entendiendo el arte como una herramienta transmisora capaz de situarnos en un proceso de compromiso, de acción y de reflexión con el que poder modelar nuestra realidad, El ataque de lo doméstico, asume la investigación artística y su práctica, como el lugar desde el que impulsarnos a buscar respuestas, alternativas que nos permitan, indagar e intervenir artísticamente en esta terrible realidad de la violencia hacia la mujer ocurrida en el hogar patriarcal hostil. Una mirada en clave feminista que nombra y da voz a la experiencia y a la biografía de las mujeres y que con su praxis, con el lenguaje plástico entre las manos, materializa, hace presente, "hace hablar a la realidad" (Hernández, 2008, p. 87), esa con la que convivimos las mujeres y a la que a veces, la teoría no alcanza a poner palabras.

Este proyecto de investigación artística, que se sumerge en el problema de la violencia machista en el hogar a través del lenguaje artístico de la performance para visibilizar su opresión y que forma parte de un proyecto mayor ${ }^{1}$, desvela el proceso de exploración, nuestra implicación y el resultado de nuestra producción artística (Hernández, 2006). Es decir, centrado, alimentado desde la reflexión teórica y entreverada por la experiencia de la violencia, se acerca y se materializa, con la práctica artística performativa, a la realidad investigada. Su desarrollo nos ha permitido expresar lo vivido, "dotar de significado al relato" (Hernández, 2006, p. 23), habitar y (re)construir nuestra historia de violencia ${ }^{2}$. Nos ha posibilitado actuar, tomar conciencia, volver y entender el arte como herramienta de transformación y de comunicación donde adivinarnos conscientes del juicio y de todo lo que nos atraviesa, pero, ante todo, su ejercicio nos ha autorizado, nos ha consentido el carácter, la conquista y la aventura de poder modelar la realidad de la violencia inscrita en nuestros cuerpos sexuados. Por tanto, bajo esta confluencia, en el desarrollo y proceso del El ataque de lo doméstico se configura un punto de encuentro entre la teoría analizada, la experiencia vivida y la práctica artística.

Dicho esto, el objetivo principal que envuelve al El ataque de lo doméstico es reflexionar, reconstruir, mostrar la violencia física, sexual e inaudita que se ejerce y legitima en el hogar patriarcal hostil y que atraviesa el cuerpo de la mujer para denunciar el universo simbólico y los privilegios sexuales de la hegemonía masculina heterosexual en los dominios domésticos. 


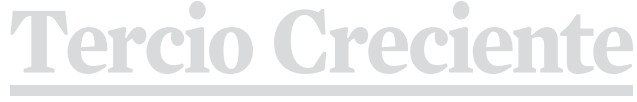

ISSN: 2340-9096

DOI: https://dx.doi.org/10.17561/rtc.n14.4
Revista de Estudios en Sociedad,

Artes y Gestión Cultural

www.terciocreciente.com

http://revistaselectronicas.ujaen.es/index.php/RTC
Para dar voz a nuestro propósito, mostrar el desarrollo, la experiencia de la violencia y la práctica artística que le da forma, la metodología llevada a cabo se ha centrado en la Investigación Artística. Además en su proceso, a la hora de indagar y anudar diferentes aspectos simbólicos y vivenciales se han ido sumando la Investigación Basada en las Artes (IBA), la perspectiva narrativa, performativa, además de un enfoque feminista.

La Investigación Artística pone en relación al investigador con la realidad, rompe con la dicotomía del sujeto y el objeto de investigación dando una mayor importancia al proceso, al contexto del que se parte y a la relación con dicha esfera circundante (Borgdorff, 2005). En ella "conceptos y teorías, experiencias y convicciones están entrelazados con las prácticas artísticas [...] De ahí que la investigación en las artes trate de articular parte de este conocimiento expresado a través del proceso creativo y en el objeto artístico mismo" (Borgdorff, 2005, p. 10).

La interrelación que nos ofrece la Investigación Artística entre el proceso, el contexto y el objeto artístico, nos ha posibilitado corporeizar conceptos, experiencias con las que relacionar y conectar el arte y la vida, levantar la crítica y desde la reflexión, buscar nuevas maneras, nuevos significados para que, a través de la práctica artística, cuestionen y den forma a la experiencia de la violencia patriarcal vivida en el hogar.

Dice Hernández que en una investigación artística, "el conocimiento puede derivar también de la experiencia. Y una forma genuina de experiencia es la artística" (Hernández, 2008, p. 90). Esta claro que el reconocimiento de la experiencia como forma de conocimiento, nos ayuda a acercarnos a la realidad, a interpretar y dar significado a lo vivido. Al fin y al cabo, la única verdad es lo que somos y nuestra experiencia, es lo único que podemos contar.

Dentro de la IBA, la perspectiva narrativa, nos ofrece nuevas formas de narrarnos. Para autores como Bruner, los procesos implicados en la construcción de significado están ligados a la experiencia vivida, a nuestra narración, así que la narrativa conlleva tanto contar una historia como un tipo de conocimiento particular y el significado creado a partir de la experiencia nos hace comprender o desafiar las visiones tradicionales de verdad, realidad y conocimiento (Bruner, 2004). Por otro lado, Blanco, nos dice que la biografía puede hablarnos tanto de una sociedad, como de una cultura, de una persona o de un grupo. Por supuesto, situando al sujeto que narra en un contexto determinado (Blanco, 2011). Por tanto, esta perspectiva, nos ofrece situarnos en nuestra historia y como tal, en un relato muchas veces común en las vidas de las mujeres. Si nuestros cuerpos contienen historias y nuestro medio para recrear la realidad es el arte, es fundamental que materialicemos nuestro relato a través de la práctica artística. Relato que toma forma en El ataque de lo doméstico y que también ha sido construido desde una perspectiva performativa.

La perspectiva centrada en la performance, presta especial atención a la experiencia vivida, al cuerpo y a la escritura mediante la narrativa auto-etnográfica (Blanco, 2012). "Propone un tipo de narración que habla a partir de uno mismo y no de uno mismo. [...] pone el énfasis en el hecho de comunicar una experiencia en la que el investigador está implicado, hasta el punto de que puede ser la experiencia del propio investigador" (Hernández, 2008, p.105).

Apostar en este proyecto por esta perspectiva performativa se debe a que dicha metodología tiene por objetivo interrogar las políticas que estructuran lo personal (Spray, 2001), dirigirse a la acción desde la reflexión, tratar de comprender nuestra subjetividad y buscar alternativas y cambios que transformen la experiencia o pongan en crisis los aspectos sociales, culturales, políticos que tratamos de investigar a través del arte y en torno a la violencia machista ocurrida en el hogar. 


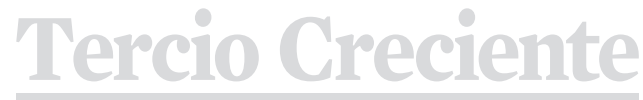

ISSN: 2340-9096

DOI: https://dx.doi.org/10.17561/rtc.n14.4
De ahí que, El ataque de lo doméstico se centre especialmente en la acción artística, donde nuestro cuerpo dialoga constantemente con la experiencia que lo habita, implicándose activamente en la confección de la práctica artística para producir significados, para exponerse e intervenir sobre las marcas que la cultura de la violencia patriarcal ha inscrito en nuestras vidas y nuestros cuerpos de mujer. Digamos con esto que El ataque de lo doméstico pone en marcha algo así como una especie de "narrativa en acción". Donde narrar la vida a través de la performance, hacer público nuestros cuerpos, es actuar, querer tocar (Denzin, 1997) al espectador/a, implicarlo/a para comprender la experiencia de la violencia instaurada en el hogar. Pero sobre todo, es querer transformar dicha experiencia, abrir nuevos cauces de relación entre nosotras, transgredir la impunidad del patriarcado ante la violencia y ser, si cabe, más libres para resignificar nuestras vidas y nuestros cuerpos. Navegar con la investigación performativa y su escritura nos ha posibilitado, como dice Vidiella: "repensar sobre nuestras posiciones, localizaciones, sobre nuestros roles como creadores y/o espectadores [...] La relación entre artista, sujeto y público nos anima a pensar sobre los métodos a través de los cuales fabricamos historias e historias del arte, para repensar los modos en los que comprendemos cómo tiene lugar el significado, y abriendo de este modo la subjetividad como algo particular e implicado en redes de relación" (Vidiella, en Hernández, 2006, p, 31).

Por otro lado, situando nuestro trabajo en una perspectiva feminista, hemos podido propiciar la reinterpretación política de nuestras vidas, cuestionar el patriarcado, las relaciones de poder, sus prácticas y la violencia que se establece entre los géneros en el espacio de lo privado.

Cabe decir, que el desarrollo artístico de El ataque de lo doméstico, está sujeto, atado a nuestra mirada, a nuestro sentir y nuestro carácter. "No ofrece una hipótesis sobre la verdad de las representaciones, sino una mirada condicionada, implicada; no afirma "así es el mundo", sino más bien "alguien lo ha contemplado así" [...] El arte transforma la percepción y configura, constituye la subjetividad" (Moraza y Cuesta, 2010, p. 9).

Con ello, entiendan que este trabajo se construye desde una mirada parcial y personal de la realidad. Es decir, con Haraway (1995), partimos de un conocimiento situado, concreto, del enfoque de nuestra realidad, nuestra experiencia vinculada al sexo, al género, a nuestra visión ante la violencia y, cómo no, a la biografía de las mujeres de nuestro entorno. Un contexto que invita a entrar en el mundo real, ha sentir el vagido de unos cuerpos femeninos, ha ser consciente de una realidad espejo que tiene que ver con realidades vividas por otras mujeres y con los patrones de opresión que han dado pie a la experiencia. Por tanto, sacamos a la luz y generamos un conocimiento vivo en torno a la vida de las mujeres. "No es una narración celebratoria de la experiencia del yo, sino un camino para establecer relaciones, desvelar vínculos y realizar aportaciones" (Hernández y Rifá, 2011). Las experiencias personales han de ser entendidas en un contexto social y cultural más amplio, en relación a los discursos sociales y culturales" (Bolivar y Domingo, 2006).

Por último, la premisa "lo personal es político", impregna el proceso y el desarrollo de nuestra investigación artística. Es decir, además de evidenciar lo que se oculta en cierto tipo de hogares, de revelar la dimensión personal de la vida, tratamos de impulsar la práctica artística como acto político, de resistencia, metáfora del cuerpo colectivo de las mujeres, que trata de impugnar lo asignado por el patriarcado a nuestros cuerpos, que pretende hacer presente la vida para politizar el dolor y la violencia e incidir en la esfera pública, en nuestras vivencias, memoria e identidad, para transformar, empoderar y liberar a las mujeres de estas estructuras de poder patriarcal. 


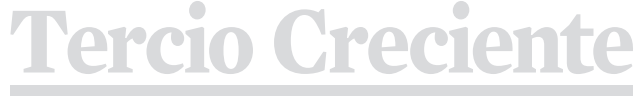

ISSN: 2340-9096

DOI: https://dx.doi.org/10.17561/rtc.n14.4
Revista de Estudios en Sociedad,

Artes y Gestión Cultural

www.terciocreciente.com

http://revistaselectronicas.ujaen.es/index.php/RTC
Por ello, resumiendo, apoyándonos en una combinación de perspectivas, artística, narrativa, performativa y feminista, con nuestro trabajo El ataque de lo doméstico, hemos tratado de dar voz a las vivencias, hemos mostrado la problemática social, la violencia que cruza y contiene nuestros cuerpos y, a su vez, hemos tratado de dar sentido a la experiencia creando prácticas artísticas performativas liberadoras con las que participar en la creación de saberes artísticos y dejar de estar, como sujeto mujer, en los márgenes del discurso de autoridad y del conocimiento y así, poder retar y encararnos con el pensamiento y la visión hegemónica patriarcal que construye nuestras vidas, poner en entredicho lo establecido y relacionar lo que somos con lo investigado.

\section{Desarrollo. El ataque de lo doméstico.}

Entrando brevemente en el tema que atraviesa a todo este proyecto, la violencia ocurrida en ciertos contextos particulares del ámbito familiar, como son los hogares con un entorno hostil, atroz e implacable, se basa muchas veces en una dinámica difícil de abarcar y de tratar debido a la superestructura de poder, a su azote jerárquico y a los mecanismos que se despliegan en él para disciplinar y someter a los cuerpos, creando muchas veces, ambientes de imposibilidad e invisibilidad para el tratamiento de dicha violencia.

Esta superestructura que garantiza el orden en los dominios domésticos a través de un sujeto masculino, adulto, heterosexual y terriblemente "macho", ungido de poder real y simbólico por nuestra cultura patriarcal y que como acto, justifica la violencia en los cuerpos de sus mujeres para mantener un cierto tipo de orden y sometimiento, siempre en beneficio propio, se encuentra instaurada en nuestra sociedad más de lo que podemos llegar a imaginar.

Sus actos de violencia y de poder ejercidos en el hogar, representan un continuo control punitivo, coercitivo y una constante dominación hacia las mujeres, niñas, niños y aquellos hombres considerados inferiores por la figura que ejerce la máxima hegemonía del poder en la familia, en el hogar. Cada abuso de poder cometido por el amo, nos dice Remedios Zafra: "no es sólo un posicionamiento que reafirma la identidad del sujeto que domina, sino que reafirma la identidad del (la) que escucha, renovando los lazos de dependencia y sumisión (reciclando los ojos del otro), estabilizando el sistema y recordando el lugar que en el juego del poder le sigue correspondiendo a cada uno" (Zafra, en Sichel y Villaplana, 2005, p. 316).

Este uso patriarcal de poder y de fuerza en el hogar, permite al amo ejercer todo tipo de vejaciones y actos violentos sobre "sus" mujeres, niñas y niños, donde la dominación, la intimidación y la sumisión se ofrecen como mandatos culturales de los cuales se espera obediencia. Esto sucede, por ejemplo, con el abuso y la violación incestuosa, la coerción en relaciones sexuales, el castigo, la paliza y la violencia por desobediencia a sus mandatos... Actos que validan el hecho violento del agresor sólo por tener una relación de parentesco o familiar con la víctima.

Bajo esta cárcel de violencia, poder y sometimiento ocurrida en el hogar patriarcal se revela El ataque de lo doméstico. Este proyecto multidisciplinar, está compuesto por videosperformances, fotografías, dibujos, grabados y textil. Los diferentes trabajos que lo componen, Rubro Despresado (2008), La mirada insolente (2009), Armas domésticas (2009-2012), El sonido de lo inefable (2010) y Receta para un desafío (2015) no pretenden más que mostrar la brutal resonancia que tiene sobre nuestros cuerpos un hogar hostil, impositivo y violento.

Agarrándonos a la performance y haciendo uso de algunas de las estrategias artísticas puestas en pie por las mujeres artistas entorno al lenguaje 


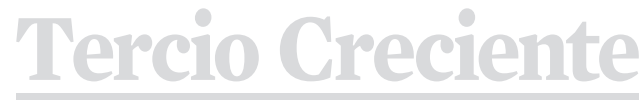

ISSN: 2340-9096

DOI: https://dx.doi.org/10.17561/rtc.n14.4 de la performance, denunciamos el ejercicio del patriarcado sobre nuestros cuerpos. Es decir, apoyándonos en estrategias artísticas performativas como: "la construcción del acontecimiento", "el papel del espectador", "el entendimiento del trauma" y "nuevos modos de evidenciar y transformar la estructura patriarcal" hemos integrado la teoría analizada de nuestra investigación con la práctica artística (Del Río, 2017) de la performance y viceversa. Estas estrategias artísticas, nos han servido de herramientas para propiciar en el proceso, prácticas de resistencias performativas con las que maniobrar, deconstruir y trasmutar dicha realidad patriarcal.

De modo que, recapitulando lo dicho y tratando de avivar todo lo que rodea a este proyecto, El ataque de lo doméstico, se vomita a partir de lo sentido a través de los cuerpos cercanos, de lo estigmatizado a lo largo de nuestras biografías, de la violencia incorporada y encarnada, de la sumisión exigida e impuesta. Con la única intención de revelarse ante aquello que nos somete, cuestionar los discursos que lo legitiman, interrogar a quien mira y silencia la tortura cotidiana, para tomar postura, para reconstruir el acontecimiento terrible de la violencia soportada e inscrita en la piel y en los huesos y poder nombrar el trauma con la única arma posible y a nuestro alcance: el discurso artístico, el lenguaje roto de la acción que revienta la lógica de los modos y comportamientos corporales. Sólo a través del lenguaje plástico, eviscerado, quebradizo y frágil del cuerpo hemos podido levantar la mirada, alzar la voz y señalar al torturador.

\subsection{Rubro despresado (2008).}

Este trabajo, realizado en 2008, se compone de la video performance Rubro despresado y de una serie de gradados realizados en el estudio y proceso de construcción de dicha pieza. En ella, exteriorizamos la espantosa y abominable violencia física y sexual ejercitada en los hogares mazmorras sobre sus mujeres y niñas.
Hay que decir, que en el proceso de creación de Rubro despresado todo tuvo una importancia vital. Se tuvo en cuenta las vivencias, las conversaciones de las mujeres cercanas en torno al ejercicio de la violencia sufrido en el hogar, el día elegido para la acción, el lugar, los materiales usados, la vestimenta elegida, opiniones de médicos que nos guiaron para ejecutar la acción sin producir un daño permanente en el cuerpo, incluso a la hora de elegir ciertas personas que tenían que intervenir en las piezas se tuvo en cuenta el porqué de esas personas y no otras. Hasta el sentimiento y la animalidad que nos envolvía ante el relato de la violencia fue representado a través de estos grabados.

Para abordar y denunciar dicha apropiación forzada de los cuerpos femeninos en el hogar patriarcal violento, en Rubro despresado, haciendo un uso estratégico de la performance, construimos nuestra realidad corporal para actuar sobre esos código culturales establecidos muchas veces como norma en el discurso machista, donde cierto tipo de hombres entienden que el cuerpo de "sus" mujeres y niñas les pertenece para ejercer sobre ellos actos de abuso o de dominación sexual.

De modo que en este trabajo, la performance se reconstruye desde la posibilidad de retornar a esos acontecimientos violentos que sobre nuestros cuerpos de mujer ha impuesto el terrorismo patriarcal en el espacio de lo doméstico. "Volver" al sentimiento original, a la experiencia internalizada para transformar, para desterrar, para hacer tangible lo que habita en la carne.

Por ello, esta video performance debe ser entendida como un acto de catarsis que no pretende más que "re-construir el acontecimiento violento", regresar a la experiencia de la violencia para vivenciar de nuevo el sentir de lo vivido. Así, transportando el tormento de la violencia sexual que habita en los cuerpos femeninos hacia un terreno limitado de lo real, en su paso a lo corpóreo, podemos delimitar, racionalizar y controlar dicho acontecimiento 


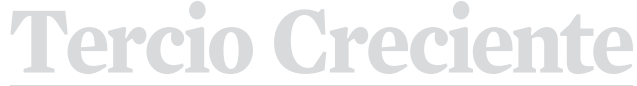

ISSN: 2340-9096

DOI: https://dx.doi.org/10.17561/rtc.n14.4
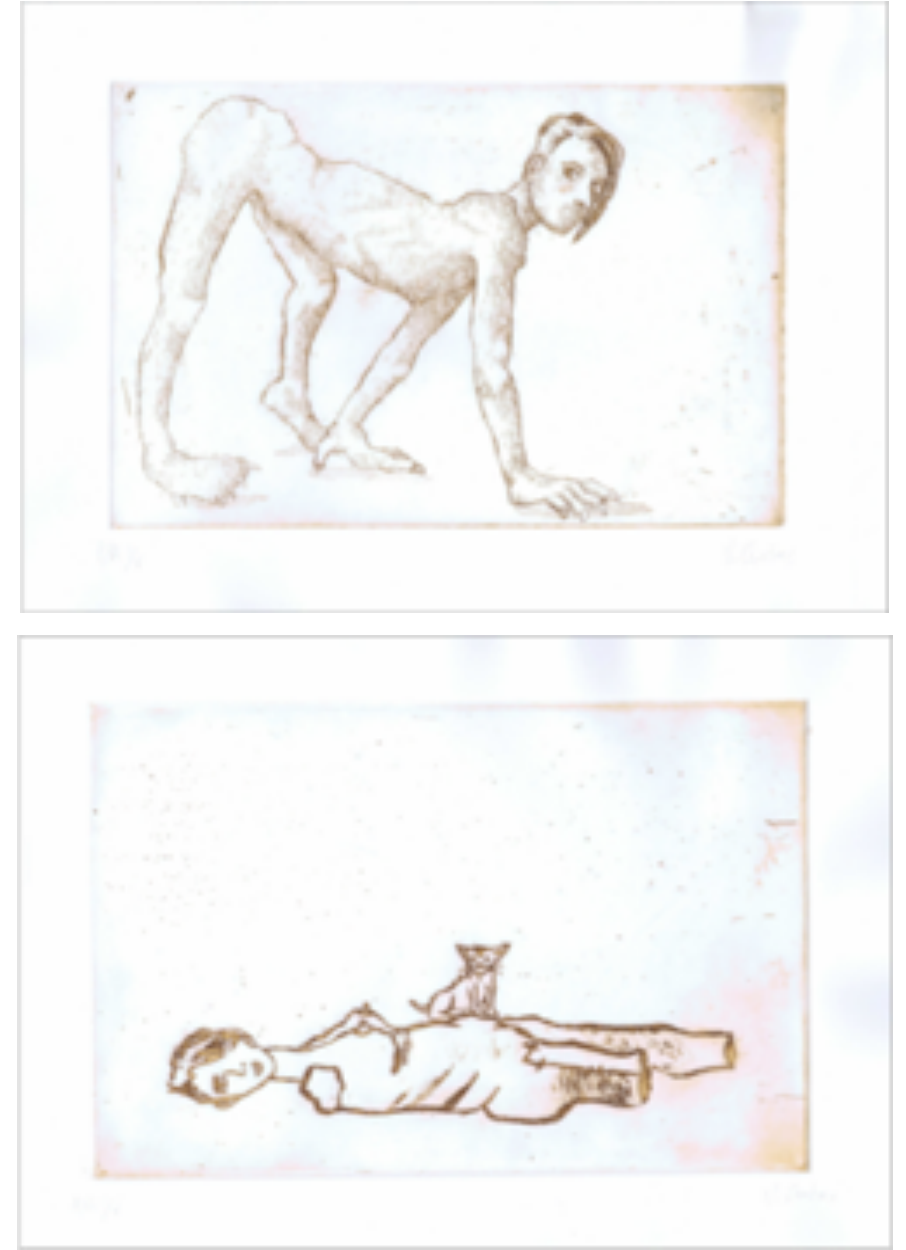

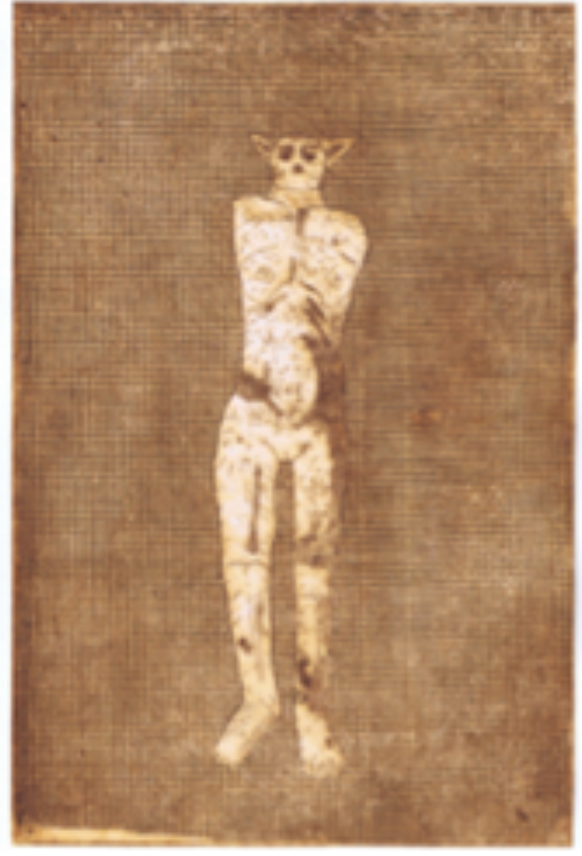

Sin título. Grabados realizados en el proceso. Tinta sepia sobre papel rosa espina. $40 \times 30 \mathrm{~cm}$. 2008. traumático dentro de nuestros propios límites, posibilitándonos con ello, reordenar nuestras narrativas, actualizando la identidad de nuestros cuerpos y liberarnos de su lacerante poder.

En Rubro despresado un escenario blanco, impoluto, lleno de instrumentales hirientes se abre al espectador/a. En escena, una mujer vestida de blanco, limpia y prepara el instrumental para someterse el ejercicio de la tortura. Se desnuda y tomando una piel de cerdo, grapa sobre su piel los orificios de su cuerpo, cerrando el acceso a éste. Una enfermera participa en la acción, extrayéndole de sus venas la consanguineidad de la sangre doliente. Sangre ferrosa con la que baña su cuerpo, restregándose como si quisiera despellejar y horadar su piel, como si teniendo al verdugo enfrente quisiera arrebatarle la potestad sobre su cuerpo y demostrarle que ahora el poder le pertenece a ella. 
ISSN: 2340-9096

DOI: https://dx.doi.org/10.17561/rtc.n14.4 www.terciocreciente.com
Trastocando los roles de víctima y torturador, se desquita, anula y libera la macabra violencia contenida.

Este uso transgresor del cuerpo en Rubro despresado, profana, exterioriza y hace tangible el terror de la memoria violenta. El dolor provocado, la violencia conscientemente autoinflingida, incómoda, confronta al espectador con aquellos acontecimiento despiadados que perturban la vida de muchas mujeres que habitan en estos hogares sádicos. Por ello, construir premeditadamente el acontecimiento violento a través de esta performance no sólo nos sustenta y nos proporciona identidad para salir del infierno, sino que además, nos lleva a gobernar, a manejar dicho calvario y a romper el código de silencio que impera en este tipo de actos tan brutales.

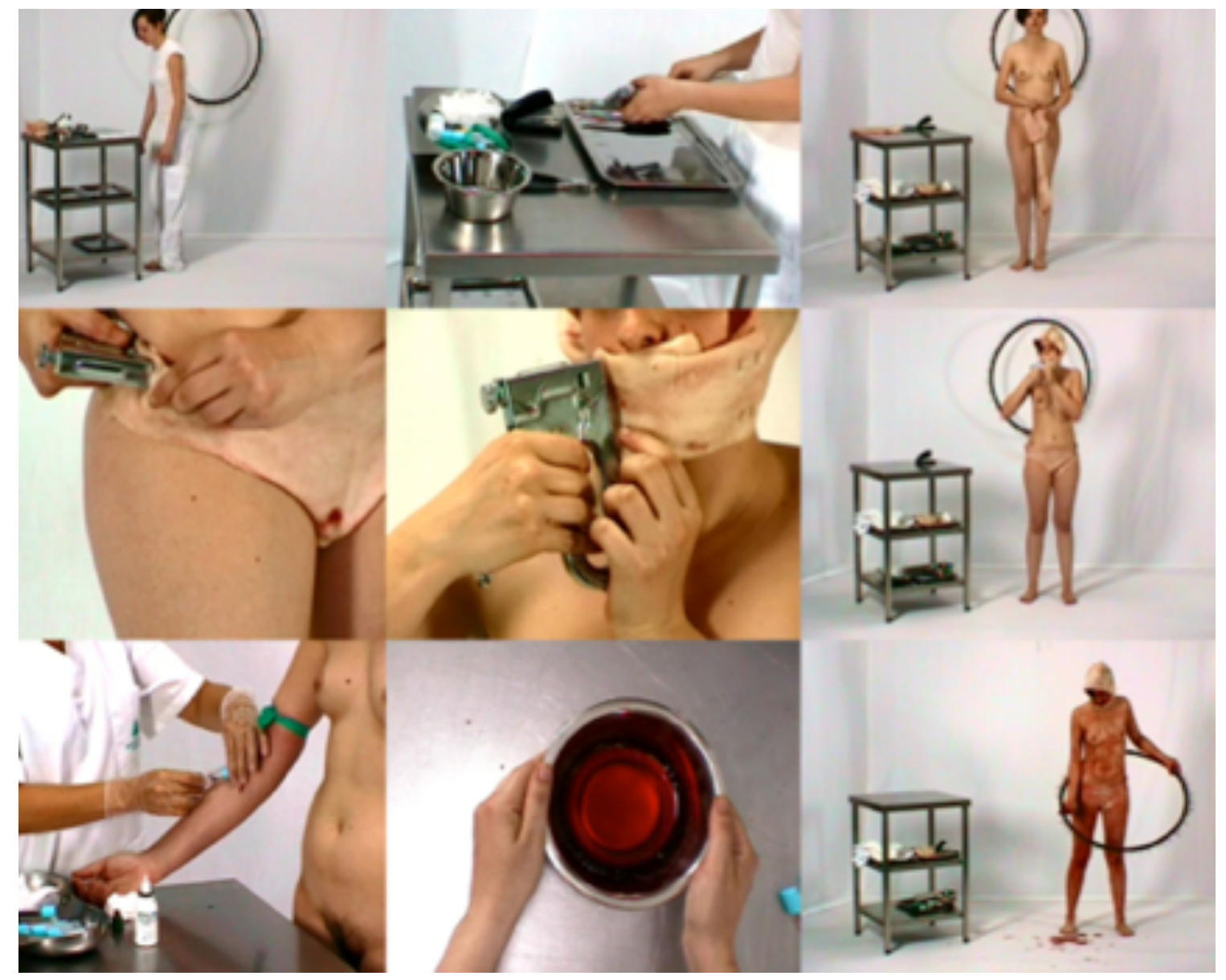

Fotogramas de la video-performance Rubro despresado, 2008. DVD, 9'40 Granada. 


\subsection{La mirada insolente (2010).}

La mirada insolente surge a raíz de la pieza Rubro despresado. Este trabajo, un conjunto de fotografías performativas a gran escala impresas en forex, muestran la violencia exponiendo la mirada de un cuerpo maltratado que sale al encuentro del espectador/a, para incomodarlo, para atraparlo y dejar de estar a salvo en la retaguardia, para que experimente, como participante testigo, la violencia contenida e inscrita en la piel de un hogar amenazante. Un "juego perverso de miradas: mirar. Mirar sólo para diluirse. Mirar(se)" (De Diego, 2011, p. 59).

El malestar, la repugnancia o el asco que pueden suscitar el uso de sus materiales, la sangre, la piel de cerdo grapada, pretenden precisamente eso, intimidar, interpelar, provocar en la audiencia dificultad para digerirlas.

La mirada insolente busca la atención y la reacción sobre la audiencia para convertirla en un sujeto activo. Por ello, hay que resaltar que en estas fotografías hacemos uso de la estrategia performativa "el papel del espectador". Con ella, de manera simbólica buscamos derrotar el papel pasivo del espectador/a y establecer una relación directa entre lo acontecido de manera individual en estas fotografías a lo colectivo vivenciado por el público.
Es decir, La mirada insolente, se dirige a la audiencia como un "cuerpo que le habla" (Picazo,1993, p. 213), la busca para implicarla en la perturbadora violencia, para atravesar la seguridad impávida de ésta y convertirla en espectadores/as de la escena. Porque donde hay violencia, el espectador/a nunca está lejos. Sólo o acompañado, está dondequiera tan presente como la violencia que contempla. Y el que no participa de modo alguno, el que no quiere ver, sabe tanto como quiere saber. Quien nada observa está libre de la molestia de la conciencia moral. No necesita reprocharse nada y se ahorra todas las incomodidades que puede acarrear el papel del testigo ocular (Sofsky, 2006).

Un dolor que mira al que mira, que devuelve y arroja la sangre al espectador para hacerlo consciente del uso que hace el sistema patriarcal del cuerpo femenino. Un retorno a la angustia, una manera de penetrar en el terreno de lo insoportable y de lo despiadado. Un deseo que no puede ser nombrado, sino mostrado "vivo" y que sólo se puede acceder a él a través de la mirada impertérrita de estas fotografías que de manera insolente y descarada, interrogan e incluso tratan de penetrar violentamente en la mirada anestesiada del espectador/a. No podemos obviar que cuanto más impone la violencia patriarcal su presencia, más condenados estamos a mirar.

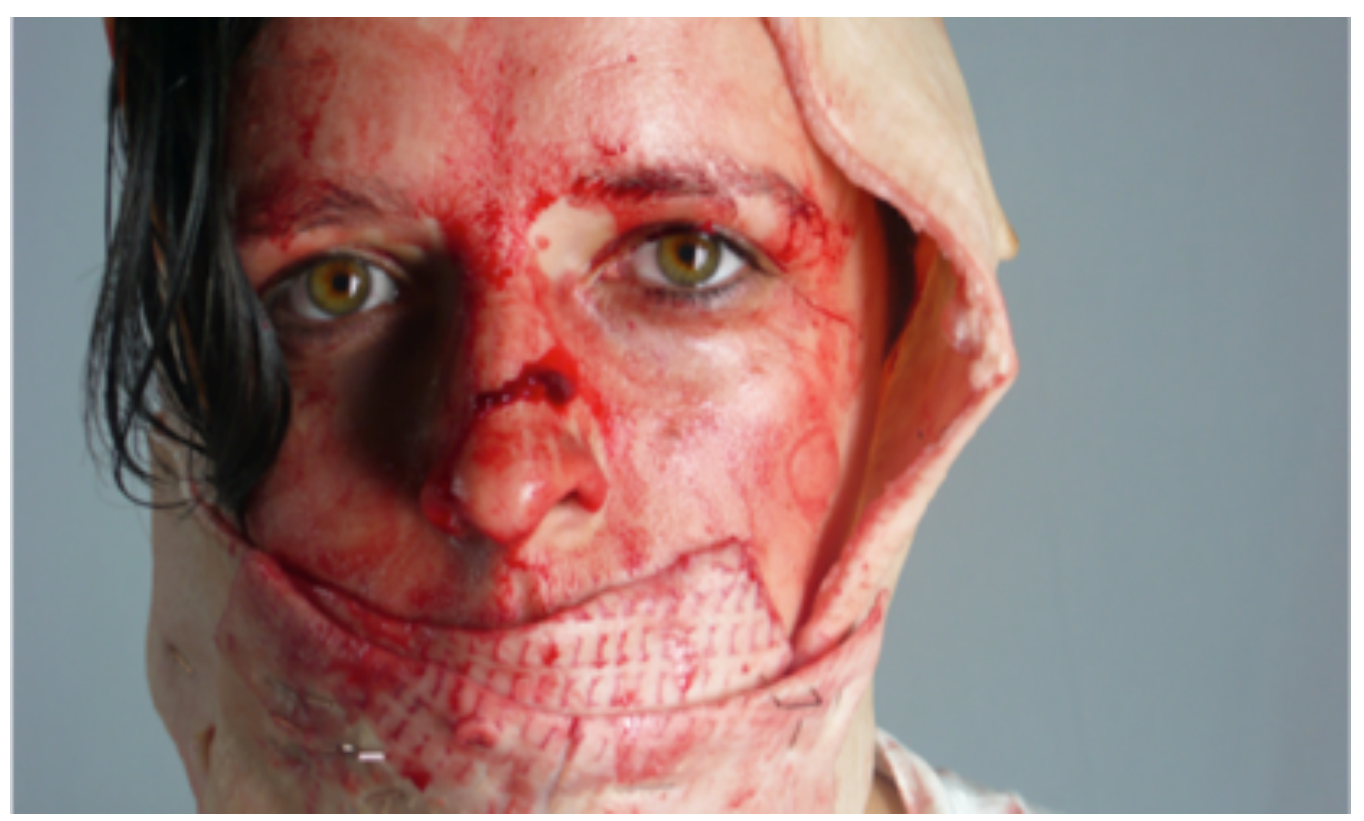

La mirada insolente IV. Fotografía impresa en forex. 100 x 150 cm. 2010. 


\section{Tercio Creciente}

ISSN: 2340-9096

DOI: https://dx.doi.org/10.17561/rtc.n14.4
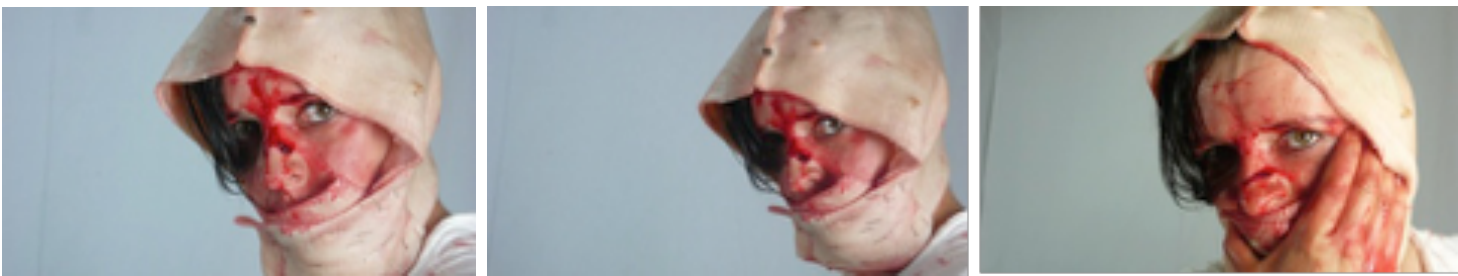

La mirada insolente VII. Plano secuencia. Fotografías impresas en forex. 30 X 50 cm cada una. 2010.

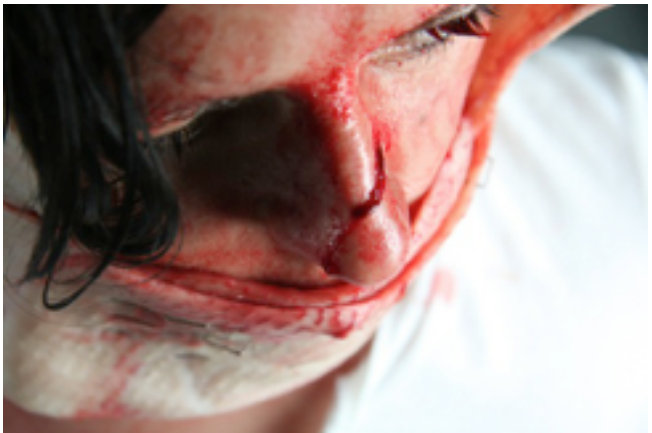

La mirada insolente II. Fotografía impresa en forex. $100 \times 150$ cm. 2010 .

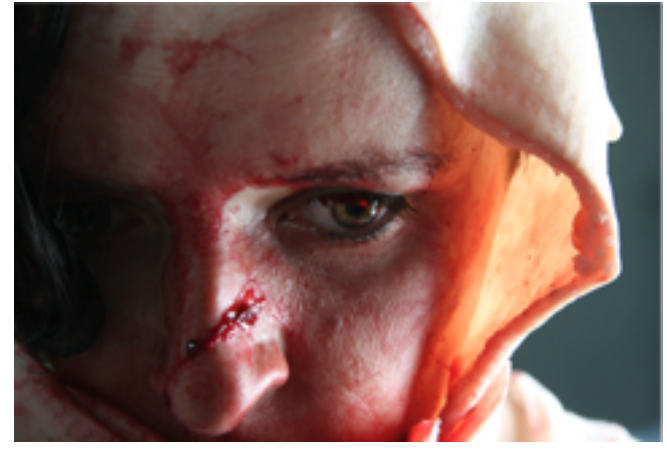

La mirada insolente I. Fotografía impresa en forex. 100 x $150 \mathrm{~cm} .2010$.
La mirada insolente V.

Fotografía impresa en forex.100 x 177 cm. 2010.

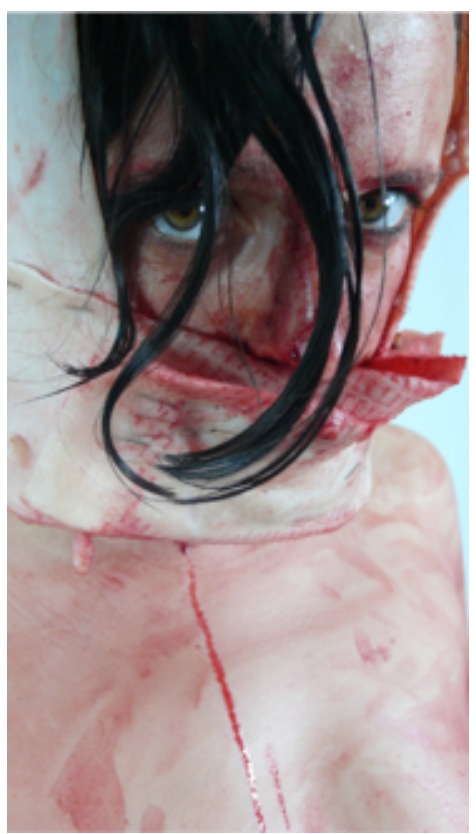

La mirada

insolente III.

Fotografía impresa en forex.100 x 177 cm. 2010. 
ISSN: 2340-9096

DOI: https://dx.doi.org/10.17561/rtc.n14.4

thata

2.3 Armas domésticas (2009-2012).

En el proceso de construcción y estudio de este proyecto, hemos elaborado esta serie de dibujos. Titulada Armas domésticas, realizada con técnicas mixtas, toma elementos domésticos para convertirlos en objetos de agresión corporal, en expositores de la carne. Una particular ventana indiscreta que expone las trampas del hogar.

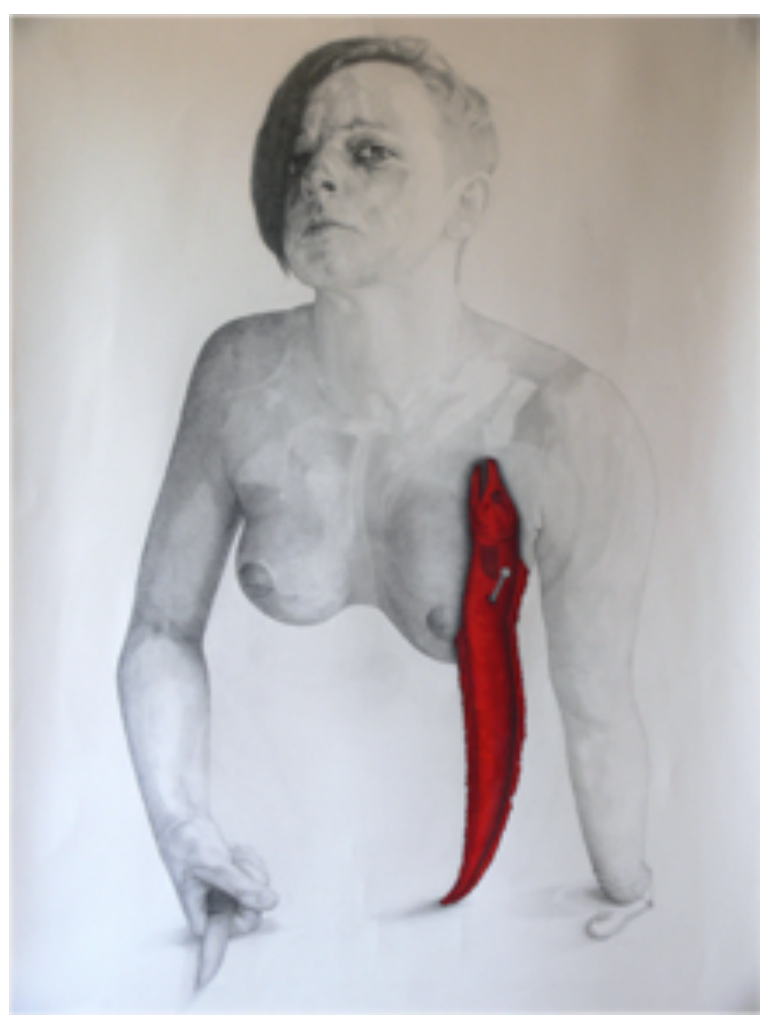

De-safío. De la serie Armas-domésticas.Técnica mixta. 70 x100 cm. 2012.

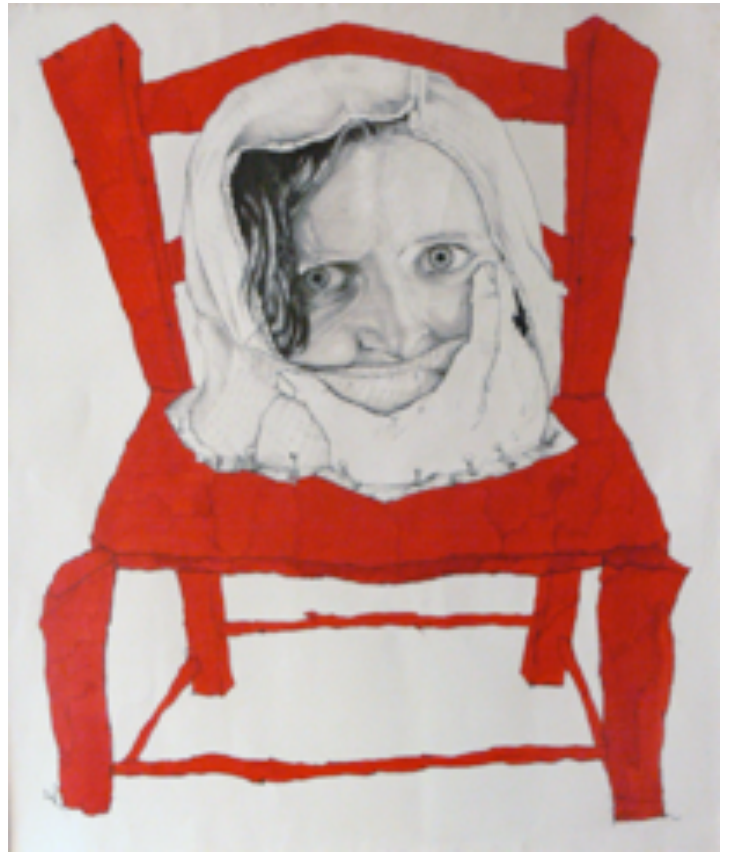

Armas-domésticas III. Técnica mixta sobre papel rosa espina. $70 \times 90 \mathrm{~cm} .2010$.

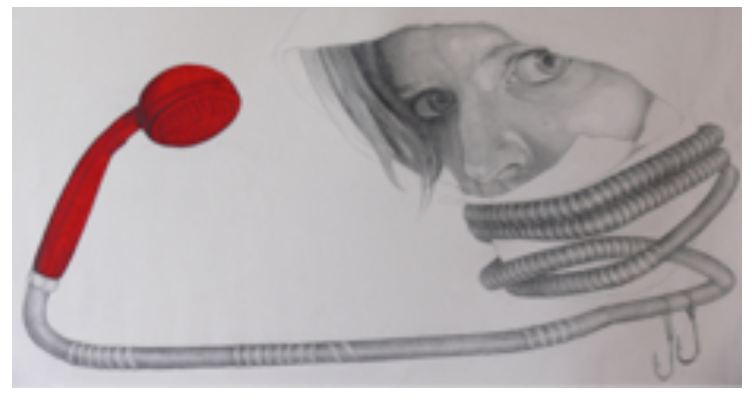

Armas-domésticas I. Técnica mixta sobre papel rosa espina. $50 \times 70 \mathrm{~cm} .2009$. 


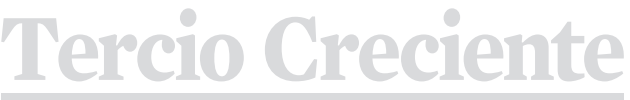

ISSN: 2340-9096

DOI: https://dx.doi.org/10.17561/rtc.n14.4

\subsection{El sonido de lo inefable (2010).}

Esta performance, realizada en 2011 en una casa abandonada, profundiza en el mutismo que reina ante el abuso sexual y las violaciones a mujeres, niñas/os, en los hogares impositivos y violentos.

La concepción de este abuso de poder sexual reposa en la inferioridad de nuestros cuerpos y en la idea de pertenencia exclusiva al hombre (Ariso y Mérida, 2010). Estas creencias construidas en nuestra cultura patriarcal predestinan a las mujeres, niñas/ os a esta indómita condena, mientras el depredador sexual es, muchas veces, invisibilizado de sus actos. Asimismo, a las víctimas, se les enseña a guardar el secreto inconfesable, haciendo cómplice al silencio, se evita la palabra. "En el campo de las agredidas, como en el de los agresores, todo el mundo da vueltas en torno al término. El resultado es un silencio cruzado" (Despentes, 2007, p. 35).

Bajo estas perversión y tabú, en El sonido de lo inefable, tomamos la performance para el "entendimiento del trauma". Su ejercicio pretende resignificar el golpe de la violencia sexual, canalizar, ahondar en su impresión para extirpar, plantar cara y combatir dicho drama.

En ella, un cuerpo desnudo se presenta con dos vasijas. Una contiene leche, que simboliza la inocencia, la niñez, la protección del hogar. La otra, contiene lenguas y sangre, elementos contaminantes y purificadores, vida y muerte, verdad y secreto, poder, dolor y silencio, pero también, por su forma y apariencia, estas lenguas representan el falo, el pene, la lanza y el crimen.
La acción comienza abriendo el grifo de la vasija de leche. Ésta goteando en el suelo, marcará la duración de la acción y el tiempo real donde se sitúa la experiencia interna. Sacando lenguas de la otra vasija, símbolo y testigo fiel del mutismo en el hogar implacable, como si estuviéramos arrancándola de entre nuestras piernas, las retorcemos violentamente con nuestras manos queriendo estrangular, desgarrar un sufrimiento sin voz, un silencio sórdido e iracundo. Con una piedra como única arma, golpe a golpe, voy clavando las lenguas en la pared. Un ataque al verdugo, a la cultura de la violación que ante la imposibilidad de encontrar en la palabra su aproximación y desvelo, golpea de manera enfurecida cada clavo para derribar el colapso emocional y sustituir el martilleo ininterrumpido por cada lamento, por cada herida abierta, por el sonido inefable del trauma que todavía permanece en los cuerpos, para así, impulsar y elevar nuestras vidas, acabar con la imposición del silencio y salir triunfante camino hacia el olvido.

"Lo que se olvida no se borra, sólo se deja de lado: se entrega al olvido. [...] La fidelidad a eso de lo que no se puede hablar, pero tampoco se puede tener en silencio, es una traición de tipo sagrado, en la cual la memoria de golpe cambia de dirección y, como remolino de viento, descubre el frente nevado del olvido" (Agamben, 2006, p. 35). 
Tercio Creciente

ISSN: 2340-9096

DOI: https://dx.doi.org/10.17561/rtc.n14.4
Revista de Estudios en Sociedad,

Artes y Gestión Cultural

www.terciocreciente.com

http://revistaselectronicas.ujaen.es/index.php/RTC
Número 14

Julio 2018

Investigación

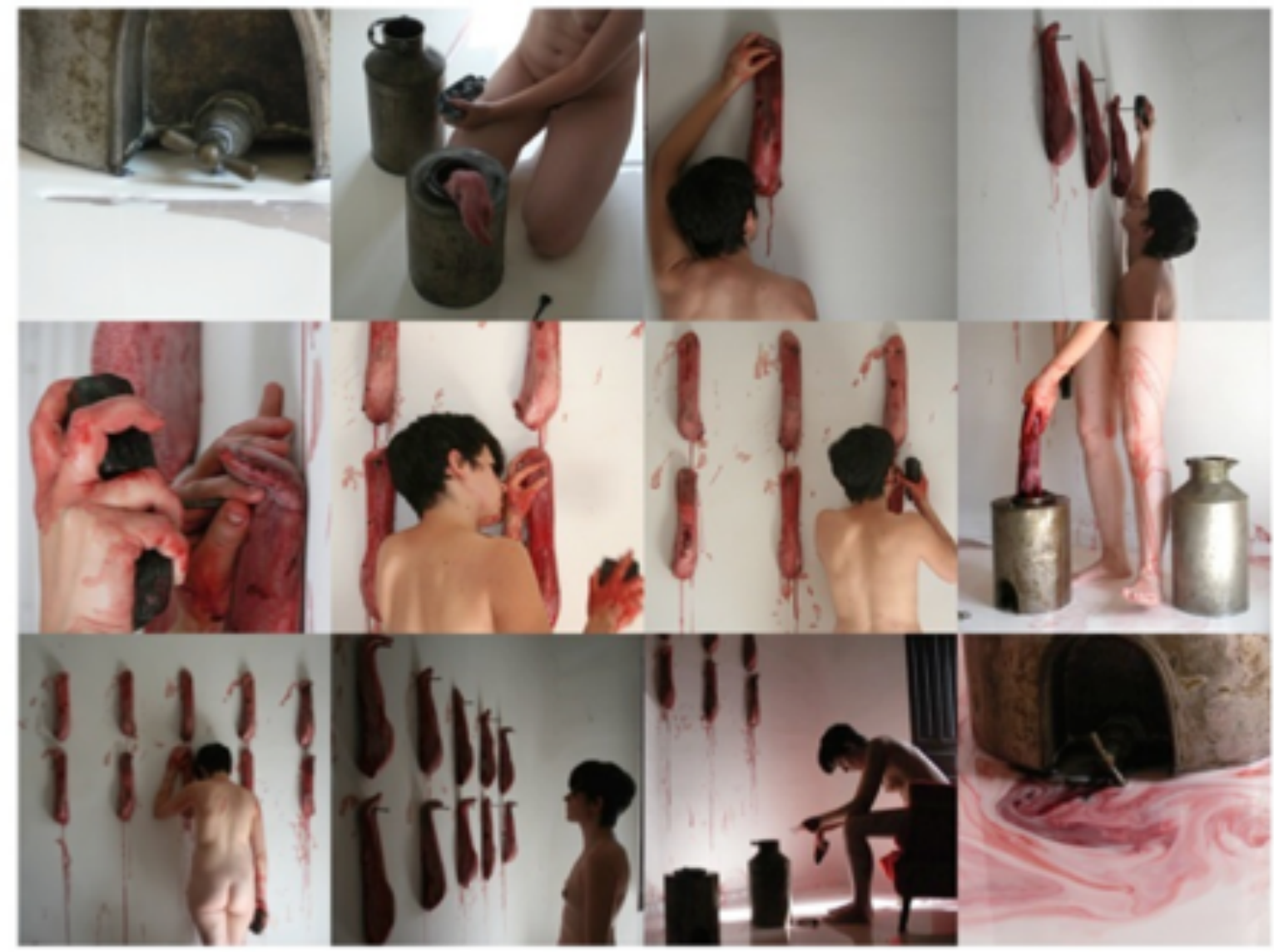

Fotografías de la performance de El sonido de lo inefable, 2010. Granada. 


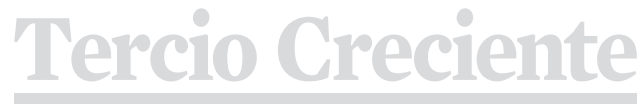

ISSN: 2340-9096

DOI: https://dx.doi.org/10.17561/rtc.n14.4

\subsection{Receta para un de-safío (2012-2015).}

Este último trabajo, formado por un conjunto de fotografías, una video performance y unas piezas textiles, se detiene en la domesticación y sujeción de las mujeres hacia la familia y las labores del hogar.

Se suele oír muy a menudo que en el hogar mandan las mujeres y cuando se es una buena esposa y madre se es "una mujer de su casa". Pero que no nos despisten las estrategias sutiles del patriarcado: "Lo doméstico no es el espacio que nos pertenece sino al que pertenecemos; no es el espacio de nuestro dominio sino el que nos domina" (Leo, en Sichel y Villaplana, 2005, p. 48).

Localizadas en el hogar y arrinconadas en actividades repetitivas, agotadoras, siempre en marcha, sin reconocimiento alguno, pero tan necesarias como vitales en nuestro día a día, las mujeres, domesticadas y adoctrinadas por el patriarcado, han interiorizado su encierro y responsabilidad sobre el hogar, sin poder ser muy conscientes de todo lo que implica. Alejadas de los beneficios de lo público y lo social, de las oportunidades, subordinadas, dependientes económicamente de sus maridos, muchas de la mujeres de nuestro entorno, se han reconocido con el paso de los años, en un cautiverio doméstico (Lagarde, 1990) que ha destruido cualquier tipo de deseos, de expectativas, de desarrollo personal sobre sus propias vidas.

Esta domesticación de las mujeres le funciona a la perfección al patriarcado. Generación tras generación, este modelo y proceso de ser madre y esposa, se convierte en un ideal para el resto de cuerpos femeninos que habitan en estos hogares heteropatriarcales y normativos. En base a esta domesticación que atraviesa nuestras vidas, a esta impotencia y ante el poco valor que se da a la labor de las mujeres en el hogar, nos aferramos al discurso del arte para empoderarlas, para transformar sus propios mundos, para desobedecer un sometimiento aprendido y desquitarlas de esa sensación inequívoca de vidas vacías, llenas de imposibilidades.
Para ello, tomamos la performance como estrategia para "evidenciar la estructura de poder patriarcal", como acto liberador, de resistencia y de cambio capaz de poner en juego otras formas discursivas y participativas más colectivas que transformen el modo de vida de las mujeres. De ahí que en este último trabajo, incorporemos a las mujeres de nuestra familia para dialogar e intervenir en sus biografías, en una vida de mujeres educadas y domesticadas para los demás.

En la video performance Receta para un de-safío (2015), tres generaciones de mujeres procedentes de una familia de tradición marinera, arraigada a sus costumbres, toma una actividad propia de su cultura y biografía, para destripar y desafiar de manera simbólica, el sometimiento y la autoridad patriarcal en el hogar.

En la performance, abuela, madre e hija comparten y se enfrentan a sus biografías a través de una misma tarea. En la mesa tres "safíos" (pez voraz, depredador, muy consumido y trabajado en nuestra familia y nuestra geografía, Cádiz) envuelto en una espacie de mortaja. La abuela, la encargada de transmitir la tradición al resto de mujeres del hogar, toma un cuchillo y uno a uno va cortando, destripando las entrañas de cada safío. Lo golpea, lo descuartiza como si ella misma se estuviera abriendo, sajando su propia piel para extirpar y extraer sus vivencias, arrancar la sumisión y desafiar el dolor.

Una vez abierto el cuerpo, la madre envuelve a cada uno de los peces en un baño de sal. Una sal que escuece, que cura lo contenido, lo que habita, encarnación también del sudor, de las lágrimas derramadas y del mar, escenario que envuelve y cruza nuestras biografías. Luego, las tres mujeres, se dirigen a la azotea de la casa, para tender al aire libre, para exponer a la luz, para presentarle al mar los tres safíos abiertos, escindidos, mutilados, metáfora de unos cuerpos que secándose al sol, aliviarán y cicatrizarán sus golpes y traumas. 


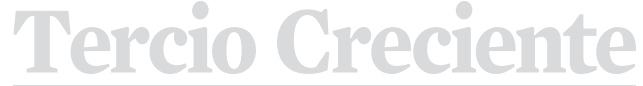

ISSN: 2340-9096

DOI: https://dx.doi.org/10.17561/rtc.n14.4
Por último, compartiendo una labor propiamente femenina, las tres mujeres, abuela, madre e hija, bordan los trapos-mortajas donde estaban envueltos los safíos, compartiendo, entretejiendo la memoria, agujas e hilos dorados que forman un mapa de silencios, de experiencias autoritarias, de un tiempo pasado lleno de tribulaciones y prisiones ocurridas en el interior del hogar impositivo y hostil de nuestro sistema y cultura patriarcal.
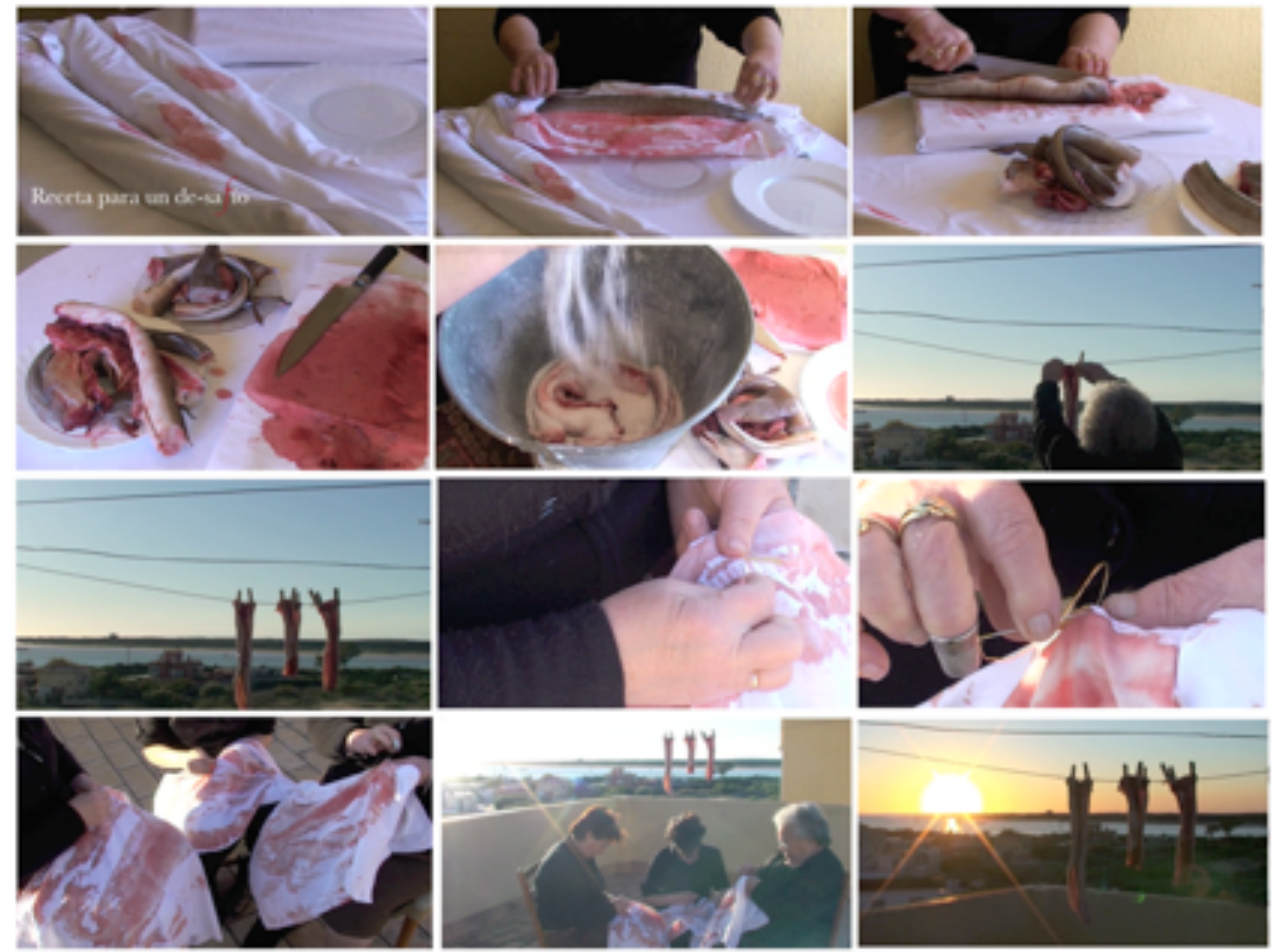

Fotogramas de Receta para un de-safío. DVD. 5'26 min. 2015. Sanlúcar de Barrameda. 


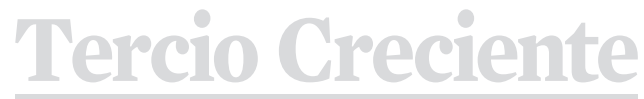

ISSN: 2340-9096

DOI: https://dx.doi.org/10.17561/rtc.n14.4
Julio 2018

Investigación

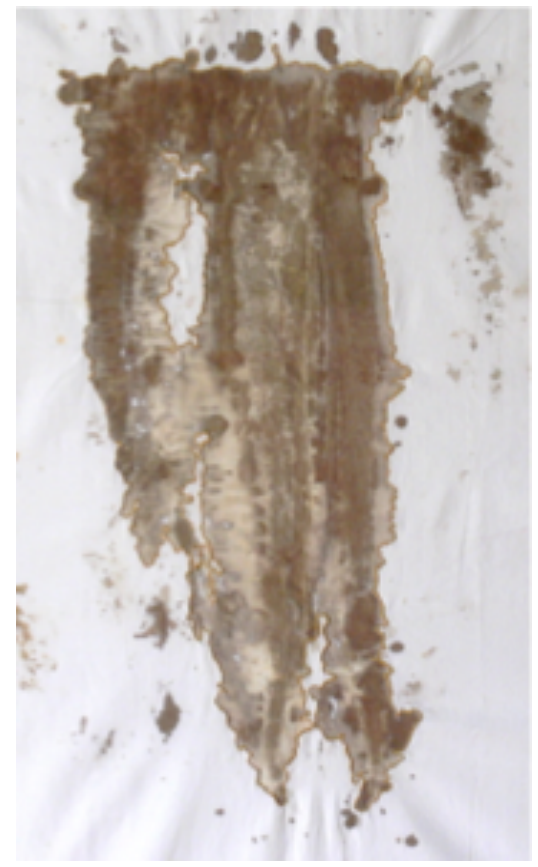

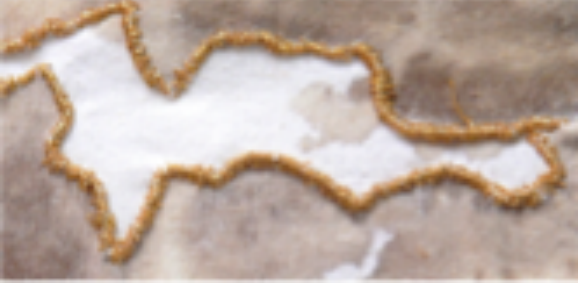

Resultado y detalle del bordajo de los trapos mortaja, 2015.
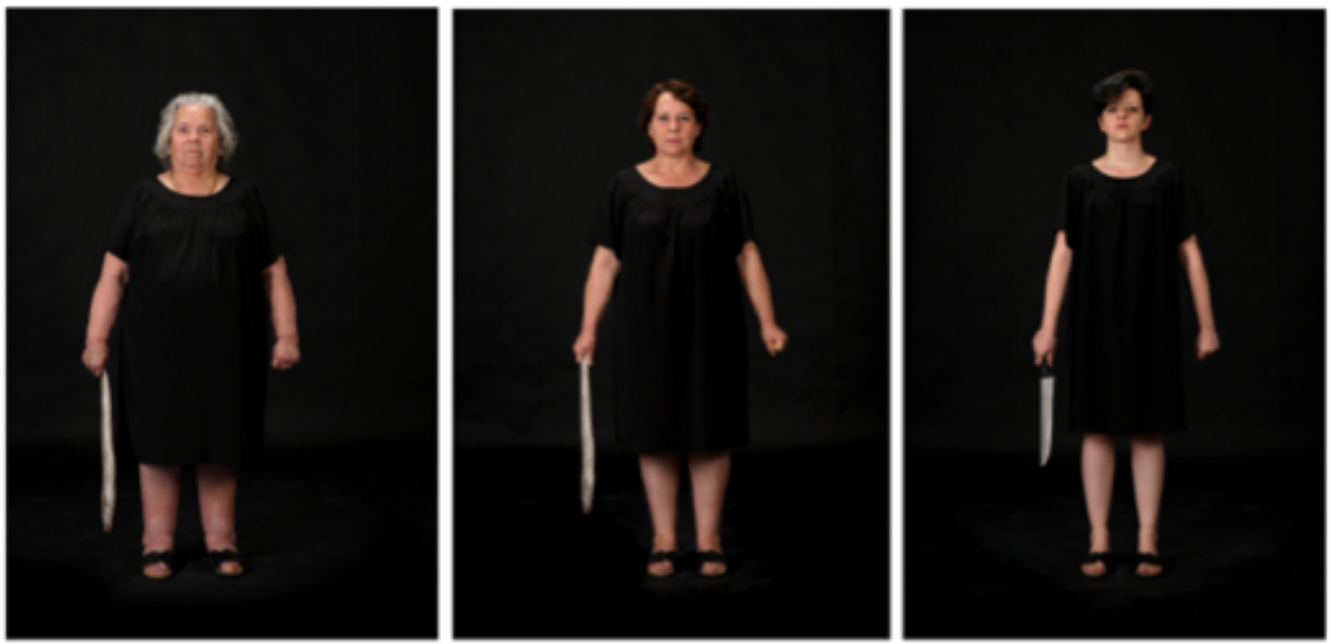

De-safío. Serie de 3 fotografías impresas en papel de algodón. Cada una $60 \times 90 \mathrm{~cm}$. Composición: 90x180 cm. 2012. 


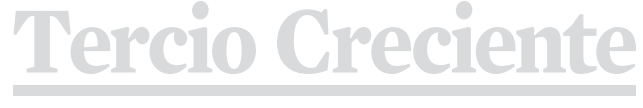

ISSN: 2340-9096

DOI: https://dx.doi.org/10.17561/rtc.n14.4
Revista de Estudios en Sociedad,

Artes y Gestión Cultural

www.terciocreciente.com

http://revistaselectronicas.ujaen.es/index.php/RTC
Concluyendo nuestro texto, después de todo lo mencionado, podemos decir que sumergirnos en el problema de la violencia machista en el hogar a través de la práctica e Investigación Artística, nos ha dado un horizonte, una alternativa con la que poder aunar teoría/vida, experiencia y práctica artística. Ésta, nos ha concedido el mejor escenario para mostrar nuestra contienda. Nos ha ayudado a hacer visible, a integrar, a modelar el sentimiento que nos envuelve, nos ha aportado esa conciencia crítica con la que actuar en esta cotidianidad de la violencia para recrearla metafóricamente, nombrarla, entenderla y manejarla.

Por ello, la representación de la violencia explícita recogida en la selección de trabajos que hemos ido viendo en el proyecto El ataque de lo doméstico (20082015), ha traspasado la piel por la necesidad de un volver y reconocerse en la herida, para que brote y se cierre, para que el sentir libere la sangre y vomite la carne ulcerada que habita en los cuerpos, haciendo coincidir al espectador en el punto exacto donde se estremece la violencia.

Sin más, el desarrollo del El ataque de lo doméstico se ha convertido para nosotras en el arma capaz de hacer saltar por lo aires la pulsión mortífera de la violencia. Rescatando el drama a través de la capacidad generativa del lenguaje de la acción, de las posibilidades para construir el acontecimiento, de la oportunidad de hacer presente, aquí y ahora, lo que en lo cotidiano se aparta, se invisibiliza y se silencia para presentárselo a la vida, para desterritorializar, desexualizar y desdomesticar mi cuerpo y el de todas aquellas mujeres (abuelas, madres, hermanas, tías, primas, amigas, vecinas, conocidas y desconocidas) inmersas en el terrible imaginario del abuso de poder por parte del monstruoso sistema patriarcal que oprime y define nuestros cuerpos femeninos.

Notas.

1 Un estudio que surge dentro la línea de investigación del Grupo HUM 425 de la Universidad de Granada, donde hemos desarrollado nuestra tesis doctoral bajo el título El cuerpo eviscerado. El ataque de lo doméstico. Acciones de mujeres (1970-2011). Para una mayor información visitar http://digibug.ugr.es/ handle/10481/48189

2. Una historia de violencia que tiene que ver con las que viven dentro y fuera de una misma, conocidas y desconocidas, por que el relato de violencia, real o simbólica, está por todas partes, en cada recoveco de nuestra cultura machista. Por ello, a lo largo de este artículo escribiremos en tercera persona del plural, bajo un "Nosotras", reflejo de todas esas mujeres, de nuestra experiencia y de las narrativas de violencia que nos envuelven. 


\section{Referencias}

Agamben, G. (2016). Una idea de la prosa. España: Adriana Hidalgo Editora.

Arisó, O. y Mérida, R. M. (2010) Los géneros de la violencia. Una reflexión queer sobre la violencia de género. Madrid: Egales.

Blanco, M. (2012). Autoetnografía: una forma narrativa de generación de conocimientos. Andamios. Revista de Investigación Social, vol. 9, núm. 19, México: Universidad Autónoma de la Ciudad de México Distrito Federal.

Blanco, M. (2011). Investigación narrativa: una forma de generación de conocimientos. Argumentos, vol. 24, nº 67, Universidad Autónoma Metropolitana Unidad de Xochimilco, Distrito Federal, México. (pp.135-156).

Bolivar, A. y Domingo, J. (2006). La investigación biográfica y narrativa en Iberoamérica: Campos de desarrollo y estado actual. Forum Qualitative Social Research. volumen 7, No. 4, Art.12. Recuperado en

http://www.qualitative-research.net/index.php/fqs/article/view/161/357

Borgdorff, H. (2005). El debate sobre la investigación en las artes. Encuentro de expertos sobre arte como investigación. Ghent, Amsterdam, Berlín y Gothenburg. Recuperado en http://www.ahk.nl/lectoraten/ onderzoek/ahkL.htm.

Bruner J. (2004). Life as narrativa. Social Research, 71,3, (pp. 691-710).

De Diego, E. (2011). No soy yo. Autobiografía, performance y los nuevos espectadores. Madrid: Ed. Siruela.

Del Río, Alfonso (2017). Consideraciones sobre la elección, definición y problematización del tema de investigación en el campo de las Bellas Artes. Arte, individuo y sociedad, 29 (1) (pp.133-147).

Denzin, N. K. (1997). Ethnographic Poetics and Narratives of the self . En Interpretative Ehtnography. London: Sage.

Despentes, V. (2007). Teoría King Kong. España: Melusina.

Gómez, M. del C., Hernández, F. y Pérez, H. (2006). Bases para un debate sobre investigación artística. Madrid: Ministerio de Educación y Cultura.

Hernández, F. (2008). La investigación basada en las artes. Propuestas para repensar la investigación en educación. Educatio Siglo XXI, №. 26. Recuperado en http://revistas.um.es/educatio/article/ view/46641/44671

Hernández, F. y Rifá, M. (Coords.). (20011). Investigación autobiográfica y cambio social. Barcelona: Octaedro. 
Lagarde, M. (1990). Cautiverios de las mujeres: madresposa, monjas, putas, presas y locas. México: UNAM.

Moraza, J. L. y Cuesta, S. (2010) Programa campus de excelencia internacional. El arte como criterio de excelencia. Modelo Ars (Art: Research: Society). Madrid: Ministerio de Educación. Secretaria General de Universidades.

Picazo, G. (Coord.). (1993). Estudios sobre performance. Sevilla: Junta de Andalucía.

Sichel, B. y Villaplana, V. (eds.). (2005). Cárcel de amor. Relatos culturales sobre la violencia de género. Madrid: Museo Nacional Centro de Arte Reina Sofía.

Sofsky, W. (2006). Tratado sobre la violencia. Madrid: Abada editores.

Spray, T. (2001). Performing Autoethnography: An Embodied Methodological Praxis. Qualitative Inquiry, volume 7, number 6, (pp. 706-732). Recuperado 